\title{
Population Pharmacokinetic Modelling and Simulation to Determine the Optimal Dose of Nanoparticulated Sorafenib to the Reference Sorafenib
}

\author{
Ki-Young Huh ${ }^{1}{ }^{\mathbb{D}}$, Se-jung Hwang ${ }^{1}$, Sang-Yeob Park ${ }^{2}$, Hye-Jung Lim ${ }^{2}$, Mir-yung Jin ${ }^{2}$, Jae-seong Oh ${ }^{1} \mathbb{D}$, \\ Kyung-Sang $\mathrm{Yu}^{1}$ and Jae-Yong Chung ${ }^{3, *}$
}

1 Department of Clinical Pharmacology and Therapeutics, Seoul National University College of Medicine and Hospital, Seoul National University, Seoul 03080, Korea; zealot648@snu.ac.kr (K.-Y.H.);

hsejung@snu.ac.kr (S.-j.H.); johan25@snu.ac.kr (J.-s.O.); ksyu@snu.ac.kr (K.-S.Y.)

2 Samyang Biopharmaceuticals Corp., Gyeonggi-do 13488, Korea; sangyeob.park@samyang.com (S.-Y.P.); hyejung.lim@samyang.com (H.-J.L.); miryung.jin@samyang.com (M.-y.J.)

3 Department of Clinical Pharmacology and Therapeutics, Seoul National University College of Medicine and Bundang Hospital, Gyeonggi-do 13620, Korea

* Correspondence: jychung@snubh.org; Tel.: +82-31-787-3955; Fax: +82-31-787-4091

check for

updates

Citation: Huh, K.Y.; Hwang, S.; Park, S.Y.; Lim, H.J.; Jin, M.; Oh, J.; Yu, K.S.; Chung, J.Y. Population Pharmacokinetic Modelling and Simulation to Determine the Optimal Dose of Nanoparticulated Sorafenib to the Reference Sorafenib.

Pharmaceutics 2021, 13, 629. https://

doi.org/10.3390/pharmaceutics13050629

Academic Editor: Gus R. Rosania

Received: 29 March 2021

Accepted: 24 April 2021

Published: 28 April 2021

Publisher's Note: MDPI stays neutral with regard to jurisdictional claims in published maps and institutional affiliations.

Copyright: (c) 2021 by the authors. Licensee MDPI, Basel, Switzerland. This article is an open access article distributed under the terms and conditions of the Creative Commons Attribution (CC BY) license (https:// creativecommons.org/licenses/by/ $4.0 /)$.

\begin{abstract}
Sorafenib, an oral multikinase inhibitor, exhibits a highly variable absorption profile due to enterohepatic reabsorption and poor solubility. SYO-1644 improved the solubility of sorafenib by nanoparticulation technology leading to enhanced bioavailability. To evaluate the pharmacokinetically equivalent dose of SYO-1644 to the reference Nexavar ${ }^{\circledR} 200 \mathrm{mg}$, a randomized, open-label, replicated two-period study was conducted in healthy volunteers. A total of 32 subjects orally received a single dose of the following assigned treatment under a fasted state in the first period and repeated once more in the second period with a two-week washout: SYO-1644 100, 150 and $200 \mathrm{mg}$ and Nexavar ${ }^{\circledR} 200 \mathrm{mg}$. Pharmacokinetic (PK) samples were collected up to $168 \mathrm{~h}$ post-dose. The PK profile was evaluated by both non-compartmental analysis and population PK method. With the final model, $2 \times 2$ crossover trial scenarios with Nexavar ${ }^{\circledR} 200 \mathrm{mg}$ and each dose of SYO-1644 ranging from 100 to $150 \mathrm{mg}$ were repeated 500 times by Monte Carlo simulation, and the proportion of bioequivalence achievement was assessed. Transit absorption compartments, followed by a onecompartment model with first-order elimination and enterohepatic reabsorption components were selected as the final model. The simulation results demonstrated that the SYO-1644 dose between 120 and $125 \mathrm{mg}$ could yielded the highest proportion of bioequivalence.
\end{abstract}

Keywords: sorafenib; pharmacokinetics; bioavailability; pharmacometrics; enterohepatic reabsorption

\section{Introduction}

Sorafenib is an oral multikinase inhibitor approved for the treatment of advanced renal cell carcinoma, hepatocellular carcinoma and thyroid carcinoma [1]. Sorafenib targets both downstream Raf serine/threonine kinases and cell surface receptor tyrosine kinases including vascular endothelial growth factor receptors [2,3]. Sorafenib has shown dosedependent antitumor activity in murine xenograft models [2]. The exposure-response relationship of sorafenib has been confirmed in several clinical trials [4,5].

Sorafenib exhibits large inter-individual variability in pharmacokinetics (PK) owing to its poor solubility [6]. The solubility of sorafenib ranges from 0.034 to $0.013 \mathrm{mg} / 100 \mathrm{~mL}$, classified as a Biopharmaceutics Classification System II (low solubility and high permeability) drug [7]. The large variability has been suggested as a source of treatment failure or excessive toxicities of sorafenib $[4,8,9]$.

SYO-1644 is a sorafenib-loaded nanoparticle formed by applying Nanoparticulation Using Fat and Supercritical Fluid (NUFS ${ }^{\mathrm{TM}}$ ) technology to improve the solubility. [10]. A higher solubility profile was achieved for SYO-1644 by optimizing the particle size and 
dissolution profile using design space [10]. This was confirmed in a pharmacokinetic study in beagle dogs [10]. SYO-1644 had an approximately 1.8 -fold increase in systemic exposure compared to the reference, Nexavar ${ }^{\circledR}$ [10]. Therefore, at a lower dose, SYO-1644 was expected to show equivalent systemic exposure to Nexavar ${ }^{\circledR}$.

However, the complex PK profile of sorafenib requires much consideration for determining the SYO-1644 dose equivalent to Nexavar ${ }^{\circledR}$ (specifically for the approved $200 \mathrm{mg}$ ). The absorption PK profile of sorafenib is characterized by multiple irregular peaks [9,11]. This makes it difficult to predict the maximum concentration $\left(\mathrm{C}_{\max }\right)$ and area under the time-concentration curve (AUCs) of sorafenib with a simple PK model, which are two crucial elements for demonstrating bioequivalence [12]. Similar complications have been addressed in highly variable drugs [13,14], such as piroxicam [15]. These intrinsic PK characteristics significantly interfere with the evaluation of formulations, reducing the statistical power of the study [14].

To determine the equivalent dose of SYO-1644 to Nexavar ${ }^{\circledR} 200 \mathrm{mg}$, a randomized, openlabel, replicated two-period study was conducted in healthy volunteers. Based on the results of the PK study, a population PK model was developed, and simulations for bioequivalence studies were conducted to estimate the optimal equivalent dose of SYO-1644.

\section{Materials and Methods}

\subsection{Study Subjects}

Healthy male subjects were enrolled aged 19-50 years with a body mass index (BMI) between 18.0 and $27.0 \mathrm{~kg} / \mathrm{m}^{2}$. Subjects were evaluated for eligibility criteria by medical interviews, vital signs (systolic and diastolic blood pressure, pulse rate, and body temperature), 12-lead electrocardiograms, physical examinations, and clinical laboratory tests. Subjects with clinically significant disease or medical history were excluded. Written informed consent form was obtained from all subjects prior to any study-related procedures. The study was approved by the Institutional Review Board of Seoul National University Hospital (Clinicaltrials.gov registration no. NCT03674060, date of approval: 20 July 2018) and conducted in accordance with the Declaration of Helsinki.

\subsection{Study Design}

A randomized, open-label, replicated two-period study was conducted (Figure 1). Subjects were randomly assigned to one of the following treatments: SYO-1644 100, 150, or $200 \mathrm{mg}$ or Nexavar ${ }^{\circledR} 200 \mathrm{mg}$. Subjects orally received a single dose of the assigned treatment in a fasted state during the first period and repeated once more during the second period with a two-week washout. Blood PK samples for sorafenib were collected at pre-dose and $0.5,1,2,3,4,6,8,10,12,24,36,48,72,96,120$, and $168 \mathrm{~h}$ post-dose in each period. Meals were provided approximately 4 and $10 \mathrm{~h}$ after the PK sample was collected.

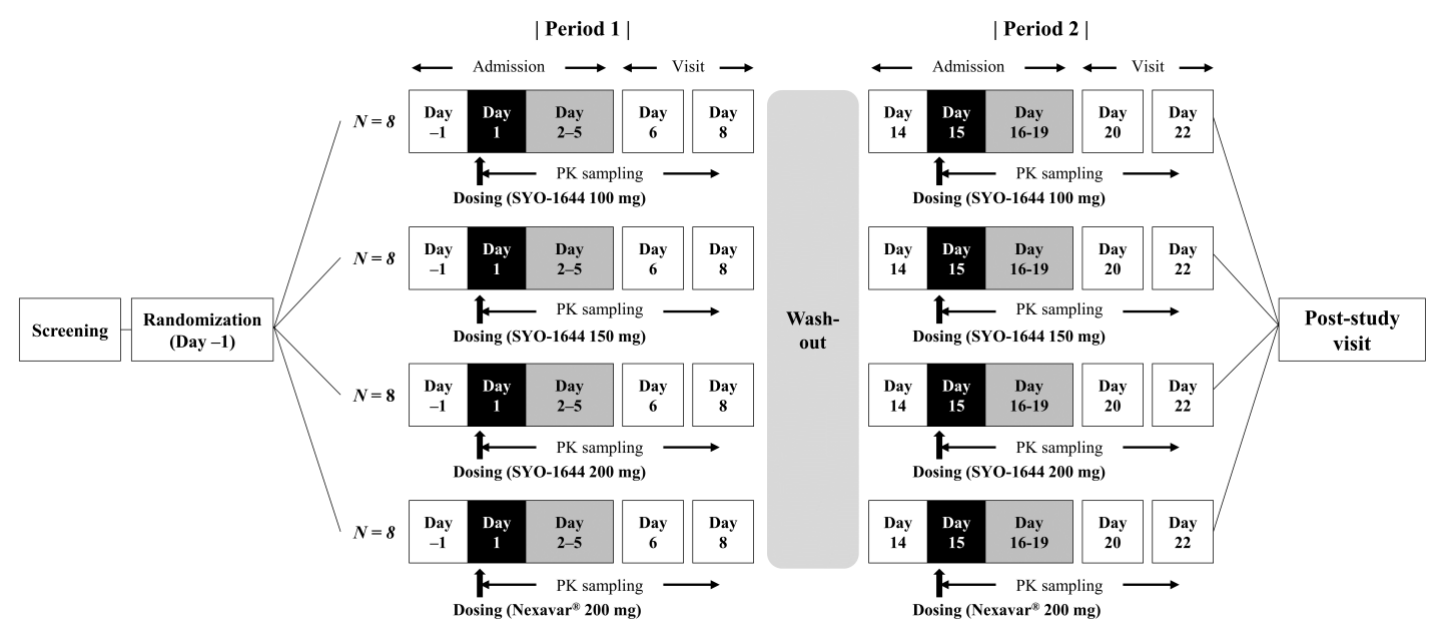

Figure 1. Study scheme. 


\subsection{Bioanalytical Method}

Blood PK samples for sorafenib were collected in sodium heparin tubes and centrifuged at $2000 \times g$ at $4{ }^{\circ} \mathrm{C}$ for $10 \mathrm{~min}$. The supernatant was separated and stored below $70{ }^{\circ} \mathrm{C}$ until the assay. The samples were prepared by protein precipitation using acetonitrile. Sorafenib-D3 was used as an internal standard. The plasma concentrations of sorafenib were determined by validated liquid chromatography (Agilent 1260 Infinity System, Agilent Technologies, Santa Clara, CA, USA) [11]. Chromatographic separation was performed using a Luna C18 column $(2.0 \mathrm{~mm} \times 100 \mathrm{~mm}, \mu \mathrm{m}$ particle size; Phenomenex, Torrance, CA, USA) at a flow rate of $0.35 \mathrm{~mL} / \mathrm{min}$. Mass spectrometry was performed in positive electrospray ionization mode using an API4000 (AB SCIEX, Framingham, MA, USA). The ion transition was monitored at $465.155 \rightarrow 270.100 \mathrm{~m} / \mathrm{z}$ for sorafenib and at $468.094 \rightarrow$ $273.200 \mathrm{~m} / \mathrm{z}$ for sorafenib-D3. The lower limit of quantification for the plasma assay was $5 \mathrm{ng} / \mathrm{mL}$. The calibration curves showed linearity in the range of 5-5000 ng/mL. The overall accuracy of the calibration curve was $92.6-106.9 \%$, and the precision was within $4.3 \%$.

\subsection{Noncompartmental Pharmacokinetic Analysis}

PK parameters for sorafenib were initially calculated by non-compartmental analysis using Phoenix ${ }^{\circledR}$ WinNonlin $^{\circledR}$ (version 7.0; Certara USA, Princeton, NJ, USA). The $\mathrm{C}_{\max }$ and time to reach $C_{\max }\left(T_{\max }\right)$ were directly obtained from the observed values. The AUC from dosing to the last measurable concentration $\left(\mathrm{AUC}_{\text {last }}\right)$ was calculated using the linear trapezoidal method for ascending concentrations and the log trapezoidal method for descending concentrations. The terminal elimination constant was estimated using linear regression. The terminal elimination half-life $\left(t_{1 / 2}\right)$ was calculated as the natural logarithm of the two divided by the estimated terminal elimination rate constant. The $\log$-transformed $\mathrm{C}_{\max }$ and $\mathrm{AUC}_{\text {last }}$ of each treatment group were analyzed using the linear mixed effect model that included the treatment group and period as fixed effects and the subject as the random effect. The intrasubject coefficient of variation $\left(\mathrm{CV}_{\text {intra }}\right)$ of each treatment was calculated from the residual error in the linear mixed-effect model using the following Equation (1):

$$
\mathrm{CV}_{\text {intra }}(\%)=100 \cdot \sqrt{\exp \left(\omega^{2}\right)-1}
$$

$\omega:$ residual error in the linear mixed effect model.

\subsection{Development of the Population PK Model}

The population PK model was developed using the nonlinear mixed effect modeling (NONMEM) software version 7.4.4. (ICON Development Solutions, Ellicott City, MD, USA). The estimation procedure was carried out using first-order conditional estimation with the interaction (FOCE-I) option. Data processing and diagnostics were conducted using R (version 3.6.3; R Core Team, Vienna, Austria), Xpose version 4 [16], and Perl-speaksNONMEM 4.9.0. [17].

The PK profiles of sorafenib showed enterohepatic reabsorption characterized by multiple peaks [2]. The proposed structure models for enterohepatic reabsorption were evaluated: one- and two-compartment models with absorption lag time, combined absorption of first- and zero-order kinetics, gall bladder-based models with continuous release, switch function, or sigmoid function [18-20]. The relative bioavailability of SYO-1644 to Nexavar ${ }^{\circledR}$ was parameterized for evaluation. Meal times (i.e., lunch and dinner) at the dosing date were also included as parameters.

Inter-individual variability (IIV) and inter-occasional variability (IOV) were described using an exponential model. The IOV was modeled using the OMEGA BLOCK step in NONMEM [21]. A combined proportional and additive residual error model was used to describe the random error in plasma concentrations [22]. 


\subsection{Evaluation of the Final Population Pharmacokinetic Model}

Goodness-of-fit plots of individual/population observed versus predicted concentrations, conditional weighted residuals (CWRES) versus population predictions and CWRES versus time after dose were graphically evaluated by each model. Visual predictive check (VPC) and bootstrapping were conducted to evaluate the predictive performance and stability of the model. VPC was conducted with 200 simulated sample subjects, and plasma concentration-time profiles were stratified by treatment group (SYO-1644 100, 150, $200 \mathrm{mg}$ or Nexavar $\left.{ }^{\circledR}\right)$. Bootstrapping was conducted with 2000 replicates to calculate the median and $95 \%$ confidence intervals for the population PK model parameter estimates.

\subsection{Simulation of Bioequivalence Trials}

With the final model, $2 \times 2$ crossover trial scenarios with Nexavar ${ }^{\circledR} 200 \mathrm{mg}$ and each dose of SYO-1644 ranging from 100 to $150 \mathrm{mg}$ ( $5 \mathrm{mg}$ interval) and the number of subjects ranging from 24 to 48 subjects ( 4 subjects interval) were repeated 500 times by Monte Carlo simulation. PK time points for the simulated trial were the same as those used in the study. $\mathrm{C}_{\max }$ and $\mathrm{AUC}_{\text {last }}$ in each simulated trial were calculated by noncompartmental analysis using the NonCompart R package [23]. Achievement of bioequivalence was defined as when the $90 \%$ CI was within 0.8-1.25 and was evaluated separately for $C_{\max }$ and $\mathrm{AUC}_{\text {last }}$. The sample proportion of bioequivalence achievement $(\widehat{\mathrm{p}})$ in the 500 simulated bioequivalence trials was utilized to estimate the $95 \%$ confidence intervals for the population proportion (p). The $95 \%$ confidence interval was estimated on the asymptotic normality of the sample proportion using the following equation were estimated with the following Equation (2) [24]:

$$
\mathrm{p}=\widehat{\mathrm{p}} \pm Z_{\alpha / 2} \sqrt{\frac{\widehat{\mathrm{p}} \cdot(1-\widehat{\mathrm{p}})}{n}}
$$

$\mathrm{Z}_{\alpha / 2}: 1-\alpha / 2$ quantile of the standard normal distribution; $\alpha$ : significance level $(=0.05)$; $\mathrm{n}$ : the number of simulated trials $(=500)$.

\subsection{Safety and Tolerability Assessments}

Safety and tolerability were assessed by adverse event monitoring, physical examinations, vital signs, 12-lead electrocardiograms and clinical laboratory tests.

\subsection{Statistical Analysis}

Baseline demographics were summarized using descriptive statistics and compared between treatment groups using the Kruskal-Wallis test. The likelihood ratio test was performed between the two nested models. A decrease in the objective function value greater than 3.84 was considered a statistically significant improvement of the model when a parameter was included in the model [25].

\section{Results}

\subsection{Subject Disposition and Demographics}

A total of 32 subjects were enrolled, and 30 subjects completed the study. Two subjects (one in SYO-1644 $100 \mathrm{mg}$ and another in the $150 \mathrm{mg}$ group) withdrew their consent after completing the first period. For noncompartmental analysis, 30 subjects who completed the study were included, and for the development of the population PK model, the 32 subjects who had at least one measurable PK concentration were included. There were no significant differences in demographics between the treatments. Mean and standard deviation ( $p$-value for Kruskal-Wallis test between treatments) of age, height, weight and body mass index of the enrolled subjects were $30.9 \pm 7.7$ (years, $p=0.6801), 173.8 \pm 5.0(\mathrm{~cm}, p=0.5503), 71.0 \pm$ $8.2(\mathrm{~kg}, p=0.9786)$ and $23.5 \pm 2.4\left(\mathrm{~kg} / \mathrm{m}^{2}, p=0.9729\right)$, respectively. 


\subsection{PK Profiles and Noncompartmental Analysis Results}

Sorafenib was absorbed irregularly and showed multiple peaks (Figure 2). The maximum concentration was reached after $4 \mathrm{~h}$ post-dose, and the second and third peaks were observed at 10 and $24 \mathrm{~h}$ post-dose, commonly in all groups. The terminal half-life ranged from 20 to $25 \mathrm{~h}$ and was similar between the groups. Nexavar ${ }^{\circledR}$ showed a lower total CV in $\mathrm{C}_{\max }$ than every dose of SYO-1644 except for total CV for SYO-1644 $200 \mathrm{mg}$. In contrast, Nexavar ${ }^{\circledR}$ showed a higher total CV of AUC last than every dose of SYO-1644. The same dose of SYO-1644 showed approximately 1.5-fold greater $\mathrm{AUC}_{\text {last }}$ than the reference $200 \mathrm{mg}$ (Table 1).

Period 1

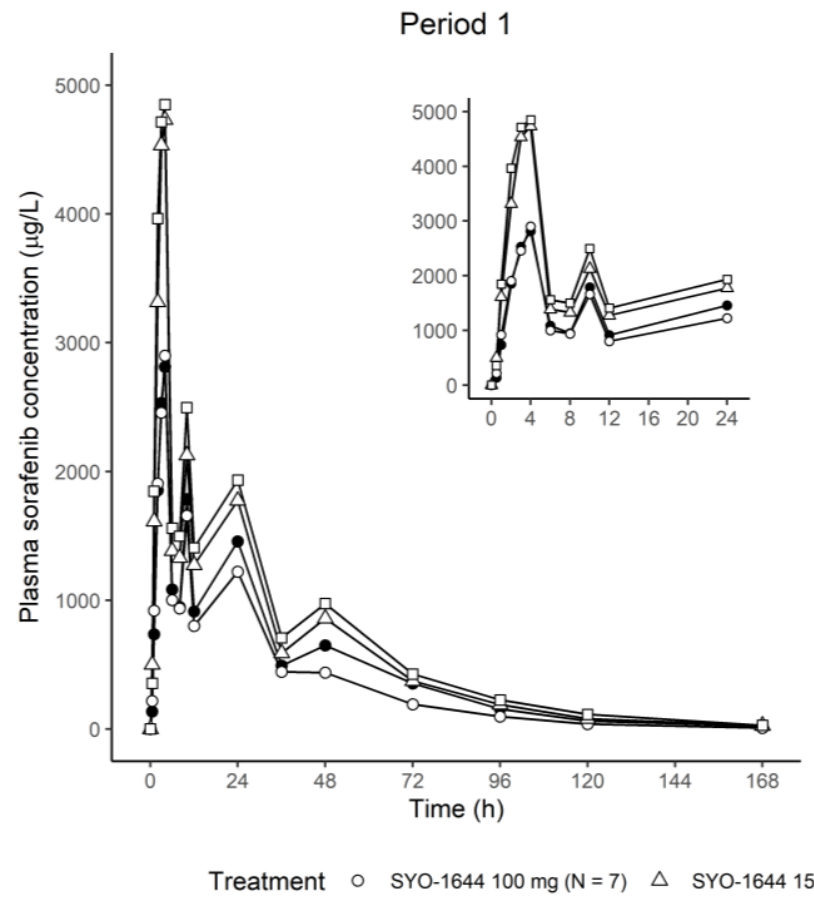

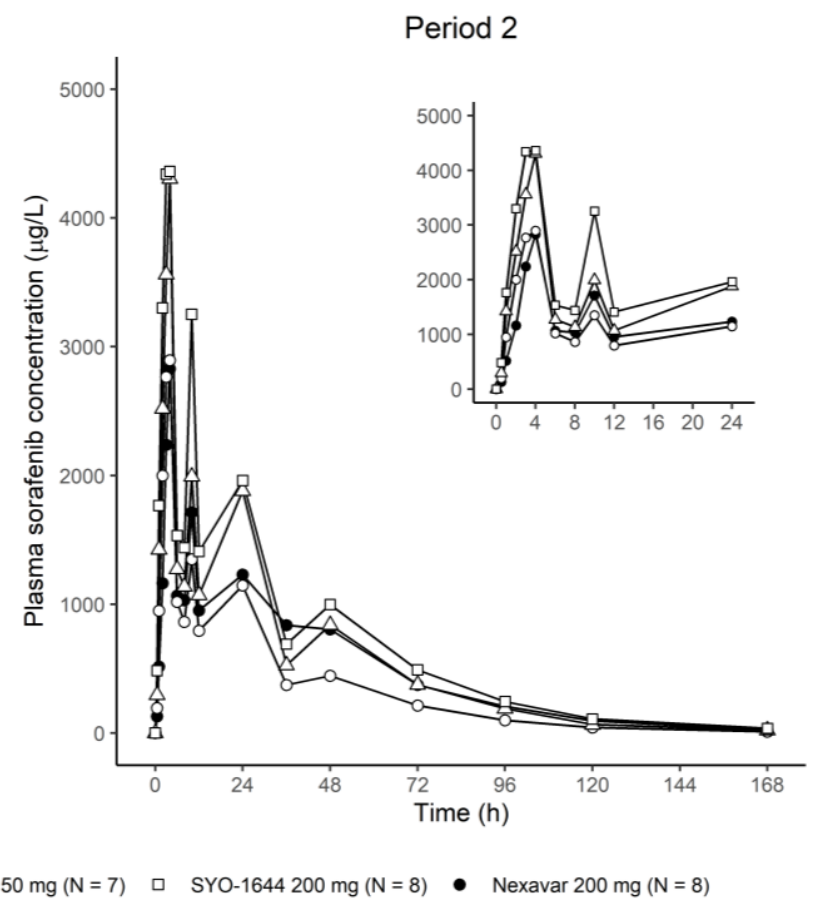

Figure 2. Mean plasma sorafenib concentration after single administration of SYO-1644 100, 150, 200 mg and Nexavar ${ }^{\circledR}$ $200 \mathrm{mg}$ (inset: time points until $24 \mathrm{~h}$ ).

Table 1. Summary of pharmacokinetic parameters of sorafenib.

\begin{tabular}{|c|c|c|c|c|}
\hline Parameters $^{\dagger}$ & $\begin{array}{l}\text { SYO-1644 } 100 \mathrm{mg} \\
\quad(N=7)\end{array}$ & $\begin{array}{l}\text { SYO-1644 } 150 \mathrm{mg} \\
\quad(N=7)\end{array}$ & $\begin{array}{l}\text { SYO-1644 } 200 \mathrm{mg} \\
\quad(N=8)\end{array}$ & $\begin{array}{c}\text { Nexavar }^{\circledR} 200 \mathrm{mg} \\
(N=8)\end{array}$ \\
\hline $\mathrm{C}_{\max }(\mu \mathrm{g} / \mathrm{L})$ & $3015.8 \pm 1076.7$ & $4899.4 \pm 2521.8$ & $5037.5 \pm 1437.8$ & $2953.4 \pm 848.1$ \\
\hline Total CV (\%) & 35.7 & 51.5 & 28.5 & 28.7 \\
\hline $\mathrm{AUC}_{\text {last }}(\mathrm{h} \cdot \mu \mathrm{g} / \mathrm{L})$ & $55,676.6 \pm 13,708.3$ & $89,241.2 \pm 30,037.6$ & $105,312.9 \pm 21,297.7$ & $73,730.1 \pm 28,864.1$ \\
\hline Total CV (\%) & 24.6 & 33.7 & 20.2 & 39.2 \\
\hline $\mathrm{T}_{\max }(\mathrm{h})$ & $4.0[2.0-10.0]$ & $4.0[2.0-4.0]$ & $4.0[2.0-10.0]$ & $4.0[3.0-10.0]$ \\
\hline$t_{1 / 2}(h)$ & $20.9 \pm 4.2$ & $24.7 \pm 8.6$ & $24.4 \pm 7.2$ & $22.2 \pm 5.1$ \\
\hline
\end{tabular}

${ }^{+}$Mean \pm standard deviation is presented for $C_{\max }, \mathrm{AUC}_{\text {last }}$ and $\mathrm{t}_{1 / 2}$. The median [minimum-maximum] value is presented for $\mathrm{T}_{\max }$. Abbreviations: $C_{\max }$, maximum plasma concentration; $\mathrm{CV}$, coefficient of variation; $\mathrm{GMR}$, geometric mean ratio; $A U \mathrm{C}_{\text {last }}$, area under the time-concentration curve from dosing to the last measurable concentration; $\mathrm{T}_{\max }$, time to reach $\mathrm{C}_{\max } ; \mathrm{t}_{1 / 2}$, terminal elimination half-life.

\subsection{Population Pharmacokinetic Analysis}

Transit absorption compartments, followed by a one-compartment model with firstorder elimination and enterohepatic reabsorption components were selected as the final model. (Table S1) Relative bioavailability (SYO-1644 to Nexavar ${ }^{\circledR}$ ) was estimated to be 1.62. The transit absorption compartments were parameterized with the mean transit time (MTT), number of transit compartments $(\mathrm{NN})$, and absorption rate constant $\left(\mathrm{k}_{\mathrm{a}}\right)$. MTT and 
the NN were estimated as $3.24 \mathrm{~h}$ and 1.72 , respectively; $\mathrm{k}_{\mathrm{a}}$ was estimated as $1.6 \mathrm{~h}^{-1}$ and showed a high intersubject CV of $87.3 \%$. Volume of distribution (V) and clearance (CL) in the central compartment were estimated as $8.17 \mathrm{~L}$ and $3.33 \mathrm{~L} / \mathrm{h}$. IIV on V and CL improved the fit of the model and was estimated to be $4.5 \%$ and $6.6 \%$, respectively. Only IOV on CL improved the fit of the model and was estimated to be $8.9 \%$ (Table 2).

Table 2. Parameter estimates of the final model and bootstrap result.

\begin{tabular}{ccc}
\hline Parameters & $\begin{array}{c}\text { Parameter Estimates } \\
\text { (Relative Standard Error, \%) }\end{array}$ & $\begin{array}{c}\text { Median of Bootstrap Results } \\
\text { (95\% Confidence Intervals) }\end{array}$ \\
\hline Relative bioavailability ${ }^{+}$ & $1.62(8.7)$ & $1.62(1.34-1.91)$ \\
MTT (h) & $3.24(5.4)$ & $3.24(2.89-3.59)$ \\
NN & $1.72(7.3)$ & $1.75(1.46-1.98)$ \\
$\mathrm{k}_{\mathrm{a}}\left(\mathrm{h}^{-1}\right)$ & $1.6(16.8)$ & $1.68(0.79-2.41)$ \\
$\mathrm{CL}(\mathrm{L} / \mathrm{h})$ & $3.33(9.6)$ & $3.23(2.6-4.06)$ \\
$\mathrm{V}(\mathrm{L})$ & $8.17(31.5)$ & $8.35(3.16-13.19)$ \\
$\mathrm{F}_{\mathrm{ent}}$ & $0.215(13.5)$ & $0.19(0.13-0.3)$ \\
$\mathrm{k}_{\text {Ehc }}\left(\mathrm{h}^{-1}\right)$ & $0.212(6.8)$ & $0.21(0.18-0.24)$ \\
$\mathrm{T}_{\mathrm{gb} 1}(\mathrm{~h})$ & $8.14(0.3)$ & $8.14(8.1-8.19)$ \\
$\mathrm{T}_{\mathrm{gb} 2}(\mathrm{~h})$ & $12.2(0.5)$ & $12.16(12.04-12.29)$ \\
IIV $\mathrm{k}_{\mathrm{a}}(\% \mathrm{CV})$ & $87.3(17.0)$ & $90.5(55.4-138.9)$ \\
IIV CL $(\% \mathrm{CV})$ & $26.1(13.2)$ & $25.0(17.7-31.8)$ \\
IIV V $(\% C V)$ & $21.5(17.1)$ & $9.0(13.2-28.2)$ \\
IOV CL $(\% \mathrm{CV})$ & $9.0(16.4)$ & $36.1(33.3-39.5)$ \\
Proportional residual error & $37.6(4.4)$ & \\
$(\% \mathrm{CV})$ & & \\
\hline
\end{tabular}

${ }^{\dagger}$ SYO-1644 to Nexavar ${ }^{\circledR}$. Abbreviations: MTT, mean transit time; NN, number of transit compartments; ka, absorption rate constant; $\mathrm{CL}$, clearance of the central compartment; $\mathrm{V}$, volume of distribution of the central compartment; $\mathrm{F}_{\text {ent }}$, fraction of enterohepatic recirculation; $\mathrm{k}_{\mathrm{Ehc}}$, enterohepatic recirculation constant; $\mathrm{T}_{\mathrm{gb} 1}$, early gall bladder emptying time; $\mathrm{T}_{\mathrm{gb} 2}$, late gall bladder emptying time; IIV, inter-individual variability; IOV, interoccasional variability; $\mathrm{CV}$, coefficient of variation.

The enterohepatic reabsorption components consisted of the gall bladder compartment combined with a steep-sloped sigmoid biliary excretion function proposed by Jain et al. [9] (Figure 3). The gall bladder compartment was linked to the central compartment with first-order transfer multiplied by the fraction of the enterohepatic compartment ( $\left.\mathrm{F}_{\mathrm{ent}}\right)$. First-order secretion of bile into the absorption compartment was parameterized with the enterohepatic reabsorption constant $\left(\mathrm{k}_{\mathrm{Ehc}}\right)$ and bile steep-sloped sigmoidal function $\left(E_{h c}\right)$. To describe the multiple peaks observed during the absorption of sorafenib, $E_{h c}$ was modified with the following two parameters: early $\left(\mathrm{T}_{\mathrm{gb} 1}\right)$ and late $\left(\mathrm{T}_{\mathrm{gb} 2}\right)$ gall bladder emptying time. $\mathrm{E}_{\mathrm{hc}}$ was assumed to be reset when $3 \mathrm{~h}$ elapsed from $\mathrm{Tg}_{\mathrm{b} 1}$. The slope of the sigmoid function was set to 40 , which was similar to the previous model [9]. $\mathrm{E}_{\mathrm{hc}}$ was defined using the following Equation (3):

$\mathrm{E}_{\mathrm{hc}}=\frac{\mathrm{TAD}^{40}}{\mathrm{TAD}^{40}+\mathrm{T}_{\mathrm{gb} 1} 40}$ when TAD $<\operatorname{Tgb}_{1}+3 \frac{\mathrm{TAD}^{40}}{\mathrm{TAD}^{40}+\mathrm{T}_{\mathrm{gb} 2} 40}$ when TAD $\geq \mathrm{Tgb}_{1}+3$

TAD: time after dose 


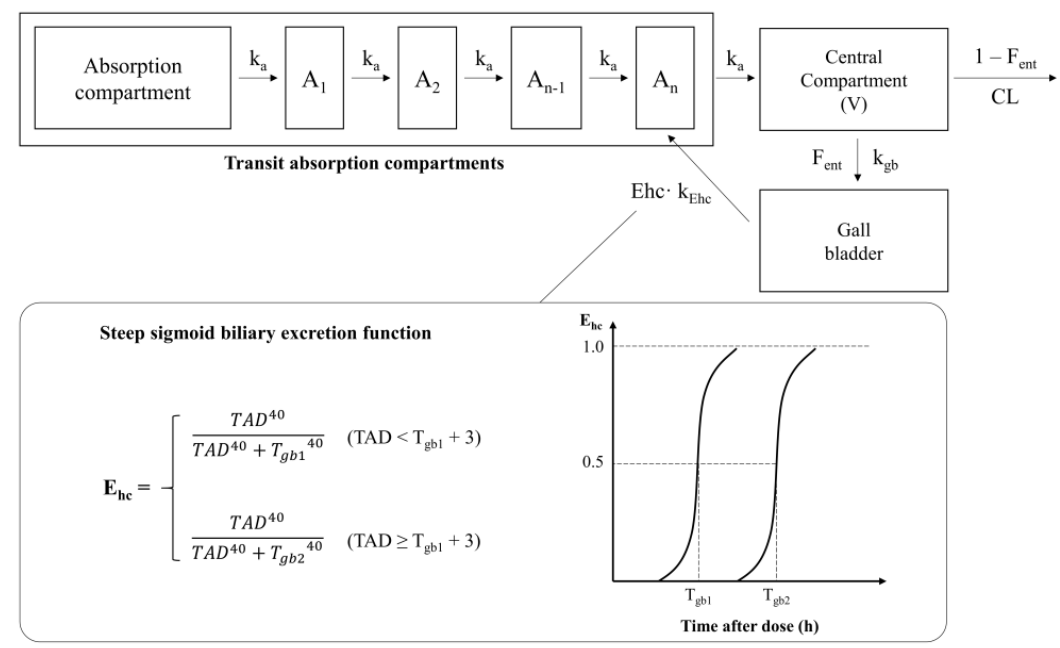

Figure 3. Structure representation of the final model. ( $\mathrm{k}_{\mathrm{a}}$, absorption rate constants; $\mathrm{CL}$, clearance of the central compartment; $\mathrm{V}$, volume of distribution of the central compartment; $\mathrm{F}_{\mathrm{ent}}$, fraction of enterohepatic reabsorption; $\mathrm{k}_{\text {Ehc }}$, enterohepatic reabsorption constant; $\mathrm{T}_{\mathrm{gb} 1}$, early gall bladder emptying time; $\mathrm{T}_{\mathrm{gb} 2}$, late gall bladder emptying time).

Based on the newly defined $\mathrm{E}_{\mathrm{hc}}, \mathrm{T}_{\mathrm{gb} 1}$ and $\mathrm{T}_{\mathrm{gb} 2}$ were estimated to be approximately 8 and $12 \mathrm{~h}$ post-dose, respectively (Figure 3 , Table 2 ).

The goodness-of-fit plots showed that the model predicted concentrations that showed a reasonable correlation with the observed concentrations. No systemic deviations in CWRES were observed (Supplementary Materials Figure S1). The VPC results showed that the model reasonably predicted the observed values for SYO-1644 100, 150 and $200 \mathrm{mg}$ and Nexavar ${ }^{\circledR} 200 \mathrm{mg}$ (Figure 4). All parameter estimates in the final model were within the $95 \%$ confidence intervals obtained by bootstrapping (Table 2 ).

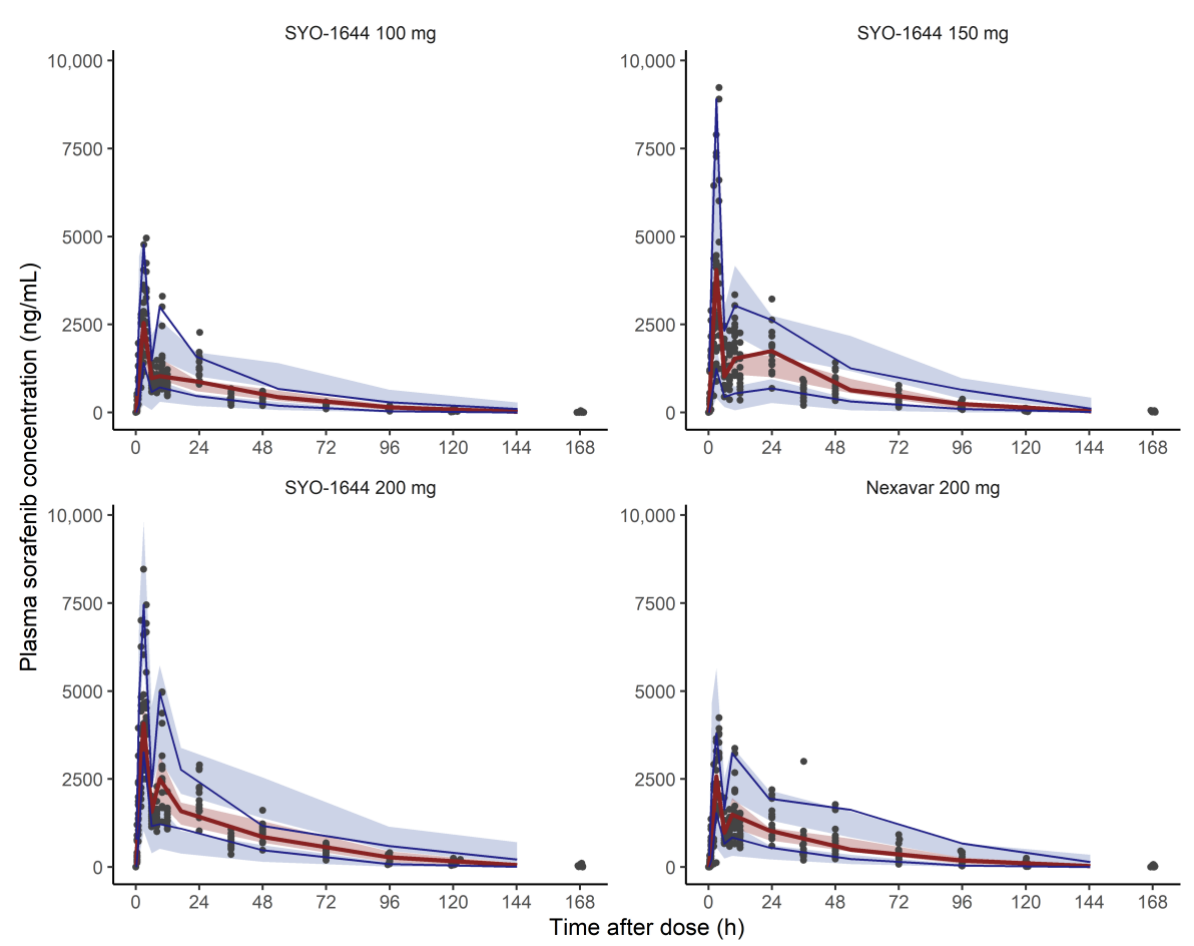

Figure 4. Visual predictive check results for the final population pharmacokinetic model. Solid blue lines represent 5 th and 95th percentile for observed data. Solid red line represents median for observed data. Blue areas represent $95 \%$ confidence intervals for 5 th and 95 th percentile of simulated data. Red areas represent $95 \%$ confidence intervals for median of simulated data. 


\subsection{Simulation Results for the Bioequivalence Trials}

The simulation results demonstrated that a SYO-1644 dose between 120 and $125 \mathrm{mg}$ yielded the highest proportion of bioequivalence achievement with Nexavar ${ }^{\circledR} 200 \mathrm{mg}$ for both $\mathrm{C}_{\max }$ and $\mathrm{AUC}_{\text {last }}$. The proportion of bioequivalence achievement was lower for $\mathrm{C}_{\max }$ than for $\mathrm{AUC}_{\text {last }}$ (Figure 5, Table S2). The mean intrasubject $\mathrm{CV}$ for $\mathrm{C}_{\max }$ was $22.0 \%$, and $\mathrm{AUC}_{\text {last }}$ was $15.7 \%$ in the simulated crossover trials (Table S3).
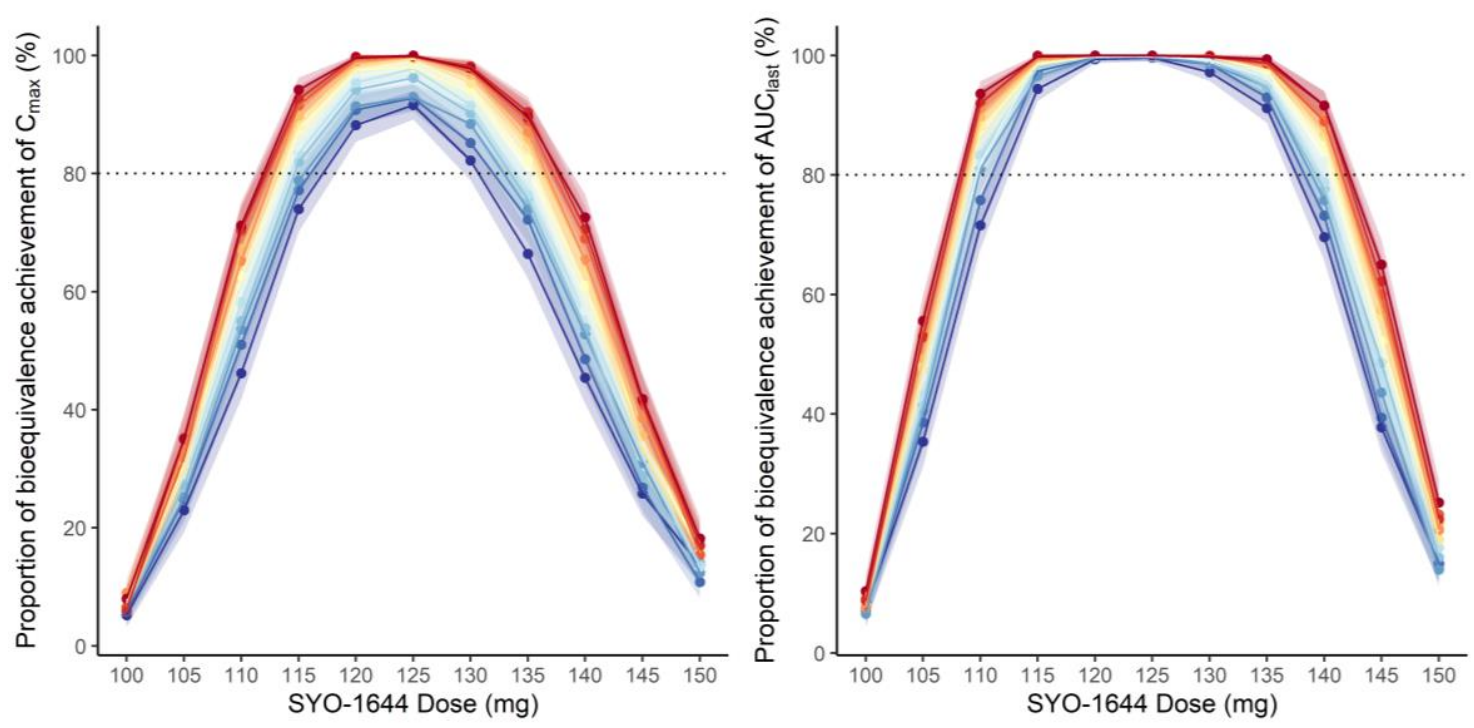

Number of subjects

Figure 5. Proportion of bioequivalence achievement (left: $C_{\max }$, right: $A \mathrm{AC}_{\text {last }}$ ) from simulated $2 \times 2$ bioequivalence trials for 500 times according to SYO-1644 dose and the number of subjects in each trial. Points represent proportion of bioequivalence achievement and areas represent $95 \%$ confidence intervals for proportion of bioequivalence achievement.

\subsection{Safety and Tolerability}

No serious adverse events or discontinuation due to adverse events were reported. A total of 13 treatment-emergent adverse events in 7 subjects and 6 adverse drug reactions in 2 subjects were reported. All adverse events were mild in severity and recovered without sequelae. No clinically significant differences were noted in the frequency and characteristics of the adverse events between treatments.

\section{Discussion}

SYO-1644 showed a 1.5-fold greater AUC than Nexavar ${ }^{\circledR}$ at the same dose level. The AUC of SYO-1644 increased in a dose-proportional manner. Both SYO-1644 and Nexavar ${ }^{\circledR}$ reached $\mathrm{T}_{\max } 4 \mathrm{~h}$ post-dose followed by multiple peaks at 10 and $24 \mathrm{~h}$ post-dose. The multiple peaks were well described by the enterohepatic reabsorption model proposed in previous literature with some modifications [9]. The simulation results indicated that SYO-1644 120 or $125 \mathrm{mg}$ could be the pharmacokinetically equivalent dose to Nexavar ${ }^{\circledR}$ $200 \mathrm{mg}$.

There were significant differences in the parameter estimates compared to those estimated from solid tumor patients [9]. The parameter estimates for CL and V in our model $(3.33 \mathrm{~L} / \mathrm{h}$ and $8.2 \mathrm{~L})$ were smaller to those reported in the solid tumor patients $(8.13 \mathrm{~L} / \mathrm{h}$ and $213 \mathrm{~L})$ [9]. The $\mathrm{F}_{\text {ent }}$ was also estimated to be smaller than the patient counterpart ( 0.215 versus 0.498 ) [9]. A difference in the patient population and dosing scheme could be a possible source of this difference. In a previous study, patients with solid tumor received 200 or $400 \mathrm{mg}$ of sorafenib twice daily [9]. In contrast, in our study, healthy volunteers received a single dose of sorafenib. Furthermore, the time-dependent 
increase in the clearance of sorafenib $[5,26]$ also needs to be considered as patients with solid tumor who received multiple oral doses of sorafenib.

Our model introduced two gall bladder emptying times $\left(T_{g b 1}\right.$ and $\left.T_{g b 2}\right)$, reflecting the relatively regular meal times in our study. The introduction of the two parameters facilitated the description of peaks observed between 8 and $12 \mathrm{~h}$ post-dose, which appeared irrespective of the formulations. The first gall bladder emptying $\left(\mathrm{t}_{\mathrm{gb}}\right)$ started approximately $2 \mathrm{~h}$ later ( $8 \mathrm{~h}$ vs. $6 \mathrm{~h}$ post-dose). Our approach was able to incorporate the steep-sloped bile secretion model of sorafenib [9] and periodic bile secretion during meal times the in the ezetimibe model [27].

The relative bioavailability estimated from the population PK model was similar to that estimated from the non-compartmental analysis ( 1.72 for $\mathrm{C}_{\max }$ and 1.51 for $\mathrm{AUC}_{\text {last}}$, respectively). As the relative bioavailability was estimated differently for $C_{\max }$ and $A U C_{\text {last, }}$, a simulation approach was adopted to coordinate both PK parameters. The simulation results showed that a SYO-1644 dose of 120-125 mg was able to achieve bioequivalence not only for $\mathrm{AUC}_{\text {last }}$ but also for $\mathrm{C}_{\text {max }}$ with $32-36$ subjects (statistical power $>80 \%$ ). However, sample sizes need to be set more conservatively as the intrasubject CVs reported in our simulation were slightly low.

This study was the first to apply a population pharmacokinetic model to design an optimal bioequivalence trial of sorafenib in healthy volunteers. In our study, we found that the intra-subject CV of sorafenib was not always larger than $30 \%$, which did not favor the replicated design to evaluate bioequivalence [28]. Based on this notion, we selected conventional $2 \times 2$ crossover trials for the simulation [29].

Our study has some limitations. This study was conducted with a small number of healthy subjects. This might limit the application of these results to the patient population. The absence of sampling points between 12 and $18 \mathrm{~h}$ limited a more precise specification of the multiple peak profiles in the population model. However, considering that typical bioavailability/bioequivalence studies are recommended in healthy subjects, the results of our study could be extrapolated to these studies. Furthermore, PK modeling and simulation supported the determination of the optimal study design and dose of SYO-1644 in a more precise manner.

The results of our study can be utilized for future comparative PK studies. From the perspective of drug development, SYO-1644 is needed to show equivalent safety and efficacy profiles to the reference Nexavar ${ }^{\circledR}$. Demonstration of pharmacokinetic equivalence could be a plausible strategy, although the exposure-response relationship must be considered.

\section{Conclusions}

The results of our study confirmed the enhanced bioavailability of SYO-1644. Transit absorption compartments, followed by a one-compartment model with first-order elimination and enterohepatic reabsorption components properly describe the PK profiles of sorafenib. A SYO-1644 dose of 120-125 mg would be the equivalent dose to Nexavar ${ }^{\circledR}$ $200 \mathrm{mg}$.

Supplementary Materials: The following are available online at https:/ /www.mdpi.com/article/10 .3390/pharmaceutics13050629/s1, Figure S1: goodness-of-fit plots., Table S1: summary of objective function values for the evaluated structure models, Table S2: proportion and its $95 \%$ confidence interval of bioequivalence achievement based on simulated $2 \times 2$ bioequivalence trials for 500 times according to SYO-1644 dose and the number of subjects in each trial, Table S3: summary of intracoefficient of variation of $\mathrm{C}_{\max }$ and $\mathrm{AUC}_{\text {last }}$ in simulated trials according to SYO-1644 dose and the number of subjects in each trial. 
Author Contributions: Conceptualization, K.Y.H., K.S.Y. and J.Y.C.; methodology, K.Y.H., K.S.Y. and J.Y.C.; software, K.Y.H., K.S.Y. and J.Y.C.; validation, K.Y.H., S.H., J.O., K.S.Y. and J.Y.C.; formal analysis, K.Y.H., K.S.Y. and J.Y.C.; investigation, K.Y.H., K.S.Y. and J.Y.C.; resources, K.Y.H., S.Y.P., H.J.L., M.J. and K.S.Y.; data curation, K.Y.H., S.H., J.O. and J.Y.C.; writing-original draft preparation, K.Y.H.; writing-review and editing, S.H., S.Y.P., H.J.L., M.J., J.O., K.S.Y., J.Y.C.; visualization, K.Y.H., K.S.Y. and J.Y.C.; supervision, J.Y.C.; project administration, K.Y.H., S.Y.P., H.J.L., M.J. and K.S.Y.; funding acquisition, K.S.Y. All authors have read and agreed to the published version of the manuscript.

Funding: The study was sponsored by Samyang Biopharmaceuticals Corp. This work was supported by the Technology R\&D Project (10067366, 'The improvement of dosage regimen and administration of targeted anticancer drugs by using nano-powderization technology') funded by the Ministry of Trade, Industry \& Energy (MOTIE, Korea).

Institutional Review Board Statement: The study was conducted in accordance with the guidelines of the Declaration of Helsinki and approved by the Institutional Review Board (or Ethics Committee) of Seoul National University Hospital (protocol code SYO-1644, 20 July 2018).

Informed Consent Statement: Informed consent was obtained from all subjects involved in the study.

Data Availability Statement: The data presented in this study are available upon request from the corresponding author. The data were not publicly available because of confidentiality.

Conflicts of Interest: Ki Young Huh, Sejung Hwang, Jaeseong Oh, Kyung-Sang Yu, and Jae-Yong Chung declare that they have no conflicts of interest. Sang Yeob Park is an employee of Samyang Biopharmaceuticals Corp. Hye Jung Lim is an employee of Samyang Biopharmaceuticals Corp. Miryung Jin is an employee of Samyang Biopharmaceuticals Corp. The funder (Samyang Biopharmaceuticals Corp.) had no influence on the design of the study and in the collection and analyses of data.

\section{References}

1. Escudier, B.; Worden, F.; Kudo, M. Sorafenib: Key lessons from over 10 years of experience. Expert Rev. Anticancer Ther. 2019, 19, 177-189. [CrossRef]

2. Keating, G.M.; Santoro, A. Sorafenib: A review of its use in advanced hepatocellular carcinoma. Drugs 2009, 69, 223-240. [CrossRef]

3. Hasskarl, J. Sorafenib: Targeting multiple tyrosine kinases in cancer. Recent Results Cancer Res. 2014, 201, 145-164.

4. Fukudo, M.; Ito, T.; Mizuno, T.; Shinsako, K.; Hatano, E.; Uemoto, S.; Kamba, T.; Yamasaki, T.; Ogawa, O.; Seno, H.; et al. Exposure-toxicity relationship of sorafenib in japanese patients with renal cell carcinoma and hepatocellular carcinoma. Clin. Pharmacokinet. 2014, 53, 185-196. [CrossRef]

5. Boudou-Rouquette, P.; Ropert, S.; Mir, O.; Coriat, R.; Billemont, B.; Tod, M.; Cabanes, L.; Franck, N.; Blanchet, B.; Goldwasser, F. Variability of sorafenib toxicity and exposure over time: A pharmacokinetic/pharmacodynamic analysis. Oncologist 2012, 17, 1204-1212. [CrossRef] [PubMed]

6. Khan, M.A.; Raza, A.; Ovais, M.; Sohail, M.F.; Ali, S. Current state and prospects of nano-delivery systems for sorafenib. Int. J. Polym. Mater. Polym. Biomater. 2018, 67, 1105-1115. [CrossRef]

7. Budha, N.R.; Frymoyer, A.; Smelick, G.S.; Jin, J.Y.; Yago, M.R.; Dresser, M.J.; Holden, S.N.; Benet, L.Z.; Ware, J.A. Drug absorption interactions between oral targeted anticancer agents and ppis: Is ph-dependent solubility the achilles heel of targeted therapy? Clin. Pharmacol. Ther. 2012, 92, 203-213. [CrossRef] [PubMed]

8. Pécuchet, N.; Lebbe, C.; Mir, O.; Billemont, B.; Blanchet, B.; Franck, N.; Viguier, M.; Coriat, R.; Tod, M.; Avril, M.F.; et al. Sorafenib in advanced melanoma: A critical role for pharmacokinetics? Br. J. Cancer 2012, 107, 455-461. [CrossRef] [PubMed]

9. Jain, L.; Woo, S.; Gardner, E.R.; Dahut, W.L.; Kohn, E.C.; Kummar, S.; Mould, D.R.; Giaccone, G.; Yarchoan, R.; Venitz, J.; et al. Population pharmacokinetic analysis of sorafenib in patients with solid tumours. Br. J. Clin. Pharmacol. 2011, 72, 294-305. [CrossRef]

10. Park, S.Y.; Kang, Z.; Thapa, P.; Jin, Y.S.; Park, J.W.; Lim, H.J.; Lee, J.Y.; Lee, S.W.; Seo, M.H.; Kim, M.S.; et al. Development of sorafenib loaded nanoparticles to improve oral bioavailability using a quality by design approach. Int. J. Pharm. 2019, 566, 229-238. [CrossRef]

11. Lathia, C.; Lettieri, J.; Cihon, F.; Gallentine, M.; Radtke, M.; Sundaresan, P. Lack of effect of ketoconazole-mediated cyp3a inhibition on sorafenib clinical pharmacokinetics. Cancer Chemother. Pharmacol. 2006, 57, 685-692. [CrossRef] [PubMed]

12. Chen, M.L.; Shah, V.; Patnaik, R.; Adams, W.; Hussain, A.; Conner, D.; Mehta, M.; Malinowski, H.; Lazor, J.; Huang, S.M.; et al. Bioavailability and bioequivalence: An fda regulatory overview. Pharm. Res. 2001, 18, 1645-1650. [CrossRef] [PubMed]

13. Polli, J.E. In vitro studies are sometimes better than conventional human pharmacokinetic in vivo studies in assessing bioequivalence of immediate-release solid oral dosage forms. AAPS J. 2008, 10, 289-299. [CrossRef] 
14. Davit, B.M.; Conner, D.P.; Fabian-Fritsch, B.; Haidar, S.H.; Jiang, X.; Patel, D.T.; Seo, P.R.; Suh, K.; Thompson, C.L.; Yu, L.X. Highly variable drugs: Observations from bioequivalence data submitted to the fda for new generic drug applications. AAPS J. 2008, 10, 148-156. [CrossRef] [PubMed]

15. Polli, J.E.; Bigora, S.; Piscitelli, D.A.; Straughn, A.B.; Young, D. 'Pavlovian' food effect on the enterohepatic recirculation of piroxicam. Biopharm. Drug Dispos. 1996, 17, 635-641. [CrossRef]

16. Jonsson, E.N.; Karlsson, M.O. Xpose-An s-plus based population pharmacokinetic/pharmacodynamic model building aid for nonmem. Comput. Methods Programs Biomed. 1998, 58, 51-64. [CrossRef]

17. Lindbom, L.; Ribbing, J.; Jonsson, E.N. Perl-speaks-nonmem (psn)—a perl module for nonmem related programming. Comput. Methods Programs Biomed. 2004, 75, 85-94. [CrossRef]

18. Okour, M.; Brundage, R.C. Modeling enterohepatic circulation. Curr. Pharmacol. Rep. 2017, 3, 301-313. [CrossRef]

19. Gabrielsson, J.; Weiner, D. Pharmacokinetic and Pharmacodynamic Data Analysis: Concepts and Applications; CRC Press: Boca Raton, FL, USA, 2001.

20. Pétricoul, O.; Cosson, V.; Fuseau, E.; Marchand, M. Population models for drug absorption and enterohepatic recycling. In Pharmacometrics: The Science of Quantitative Pharmacology; Ette, E.I., Williams, P.J., Eds.; John Wiley \& Sons, Inc.: Hoboken, NJ, USA, 2007; pp. 345-382.

21. Karlsson, M.O.; Sheiner, L.B. The importance of modeling interoccasion variability in population pharmacokinetic analyses. J. Pharmacokinet. Biopharm. 1993, 21, 735-750. [CrossRef] [PubMed]

22. Proost, J.H. Combined proportional and additive residual error models in population pharmacokinetic modelling. Eur. J. Pharm. Sci. 2017, 109, S78-S82. [CrossRef]

23. Gomeni, R.; Bressolle-Gomeni, F. Comparison of alternative population modeling approaches for implementing a level a ivivc and for assessing the time-scaling factor using deconvolution and convolution-based methods. AAPS J. 2020, 22, 1-13. [CrossRef]

24. Agresti, A.; Coull, B.A. Approximate is better than "exact" for interval estimation of binomial proportions. Am. Stat. 1998, 52, 119-126.

25. Kowalski, K.G.; Hutmacher, M.M. Efficient screening of covariates in population models using wald's approximation to the likelihood ratio test. J. Pharmacokinet. Pharmacodyn. 2001, 28, 253-275. [CrossRef] [PubMed]

26. Arrondeau, J.; Mir, O.; Boudou-Rouquette, P.; Coriat, R.; Ropert, S.; Dumas, G.; Rodrigues, M.J.; Rousseau, B.; Blanchet, B.; Goldwasser, F. Sorafenib exposure decreases over time in patients with hepatocellular carcinoma. Investig. New Drugs 2012, 30, 2046-2049. [CrossRef] [PubMed]

27. Ezzet, F.; Krishna, G.; Wexler, D.B.; Statkevich, P.; Kosoglou, T.; Batra, V.K. A population pharmacokinetic model that describes multiple peaks due to enterohepatic recirculation of ezetimibe. Clin. Ther. 2001, 23, 871-885. [CrossRef]

28. European Medicines Agency, Sorafenib Film-Coated Tablets 200 mg Product-Specific Bioequivalence Guidance [internet]. Available online: Https:/ / www.Ema.Europa.Eu/en/sorafenib-product-specific-bioequivalence-guidance (accessed on 25 June 2020).

29. Karalis, V.; Symillides, M.; Macheras, P. Bioequivalence of highly variable drugs: A comparison of the newly proposed regulatory approaches by fda and ema. Pharm. Res. 2012, 29, 1066-1077. [CrossRef] [PubMed] 